\title{
Deformation-Induced Phase Transformations
}

\author{
Elena Pereloma ${ }^{1, *(\mathbb{D})}$ and Ilana Timokhina ${ }^{2}$ \\ 1 Electron Microscopy Centre, Australian Institute for Innovative Materials, University of Wollongong, \\ NSW 2500, Australia \\ 2 Institute for Frontier Materials, Deakin University, Geelong, VIC 3217, Australia; \\ ilana.timokhina@deakin.edu.au \\ * Correspondence: elenap@uow.edu.au
}

Received: 26 October 2018; Accepted: 30 October 2018; Published: 31 October 2018

check for updates

\section{Introduction and Scope}

Phase transformations are significant phenomena determining the final properties of a wide range of materials. They can occur under various external conditions, both thermal and mechanical. Deformation-induced phase transformations commonly take place in service or during the processing of parts made from steels or non-ferrous alloys. These might include deformation-induced ferrite formation in steels, transformations of austenite ( $\gamma$, face centred cubic: FCC) to $\varepsilon$ (hexagonal close packed: $\mathrm{HCP}$ ) or $\alpha^{\prime}$ martensite (base centred cubic: BCC, or base centred tetragonal: BCT) in steels, transformations of the $\beta$ phase (BCC) in metastable Ti alloys to $\alpha^{\prime \prime}$ martensite (orthorhombic) or $\omega$ phase (hexagonal); austenite (FCC) to martensite (BCC) in Fe-Pt alloys, and cubic $\mathrm{B} 2 \rightarrow$ monoclinic B19' martensitic transformation in NiTi alloys. In the majority of cases, these transformations proceed rapidly via a shear mechanism. Such transformations may have a remarkable effect on the work hardening behaviour, the plasticity of materials, and even the shape memory effect underwriting the spectrum of material properties required for a wide range of applications. Thus, the aim of this issue is to provide both the reviews of these phenomena and an introduction to the latest research achievements uncovering the fundamental aspects of these complex transitions.

\section{Contributions}

The present Special Issue includes two review papers [1,2] and seven scientific papers [3-9] covering compositional, microstructural, and crystallographic aspects of deformation-induced phase transformations in titanium alloys [2,5,6], steels [3,4,7-9], and shape memory alloys [1].

A comprehensive examination of crystallography, displacive mechanisms, and the reversibility of martensitic transformations in shape memory alloys is given in the review by Dunne [1]. In particular, the effect of austenite ordering on martensite formation in $\mathrm{Fe}_{3} \mathrm{Pt}$ alloy was highlighted [1].

Deformation-induced martensitic transformation plays a remarkable role in the so-called Transformation-Induced Plasticity (TRIP) effect $[6,7]$ in both advanced steels and metastable Ti alloys $[2,5,6]$. However, to date, the clear understanding of various factors influencing the occurrence of this event remains elusive as a result of the complexity of their different interactions. Both material-dependent parameters, such as a stacking fault energy of austenite in steels and $\beta$ phase stability in Ti alloys [2,5], as well as external/loading conditions (temperature, uniaxial tensile, plane strain compression, cyclic loading, high pressure torsion) $[2,4-7]$ are examined in this Special Issue.

For several years, not only deformation-induced martensitic transformations, but also dynamically-induced ferrite transformations have attracted significant interest. This topic is addressed in Reference [8].

Innovative methodologies including advanced characterisation techniques (high-resolution transmission electron microscopy, electron back-scattering diffraction, small-angle neutron scattering, 
and digital image correlation) were used in the papers of this Special Issue, which assisted the elucidation of the studied phenomena both ex situ and in situ.

\section{Conclusions and Outlook}

There is a continuous demand for the development of new materials with specific sets of structural and functional properties. Such materials are required for applications in the automotive, aerospace, biomedical, and building industries. Optimisation of material properties can be achieved by controlling the phase transformations. This is becoming more important as the microstructures of modern steels contain multiple phases and so are becoming more complex. Thus, further research into understanding the fine details of these transformations, the interactions between the phases, and their responses in different service conditions is crucial.

As guest editors, we would like express our gratitude to all the contributing authors for making this Special Issue a valuable reference source on this topic. We want to extend our special thanks to the Metals editorial team, in particular to Ms. Hollie Huang, for their assistance and support during the preparation of this Special Issue.

Conflicts of Interest: The authors declare no conflict of interest.

\section{References}

1. Dunne, D. Martens-ite. Metals 2018, 8, 395. [CrossRef]

2. Kolli, R.P.; Devaraj, A. A Review of Metastable Beta Titanium Alloys. Metals 2018, 8, 506. [CrossRef]

3. Jeon, J.B.; Chang, Y.W. Effect of Nitrogen on Deformation-Induced Martensitic Transformation in an Austenitic 301 Stainless Steels. Metals 2017, 7, 503. [CrossRef]

4. Ma, Y.; Song, W.; Zhou, S.; Schwedt, A.; Bleck, W. Influence of Intercritical Annealing Temperature on Microstructure and Mechanical Properties of a Cold-Rolled Medium-Mn Steel. Metals 2018, 8, 357. [CrossRef]

5. Kilmametov, A.R.; Ivanisenko, Y.; Straumal, B.B.; Gornakova, A.S.; Mazilkin, A.A.; Hahn, H. The $\alpha \rightarrow \omega$ Transformation in Titanium-Cobalt Alloys under High-Pressure Torsion. Metals 2018, 8, 1. [CrossRef]

6. Samiee, A.; Casillas, G.; Ahmed, M.; Savvakin, D.G.; Naseri, R.; Pereloma, E. Formation of Deformation-Induced Products in a Metastable- $\beta$ Titanium Alloy during High Temperature Compression. Metals 2018, 8, 100. [CrossRef]

7. Chen, T.C.; Chen, S.T.; Tsay, L.W.; Shiue, R.K. Correlation between Fatigue Crack Growth Behavior and Fracture Surface Roughness on Cold-Rolled Austenitic Stainless Steels in Gaseous Hydrogen. Metals 2018, 8, 221. [CrossRef]

8. Aranas, C., Jr.; Rodrigues, S.; Fall, A.; Jahazi, M.; Jonas, J. Determination of the Critical Stress Associated with Dynamic Phase Transformation in Steels by Means of Free Energy Method. Metals 2018, 8, 360. [CrossRef]

9. Song, W.; Houston, J.E. Local Deformation and Mn-C Short-Range Ordering in a High-Mn Fe-18Mn-0.6C Steel. Metals 2018, 8, 292. [CrossRef]

(C) 2018 by the authors. Licensee MDPI, Basel, Switzerland. This article is an open access article distributed under the terms and conditions of the Creative Commons Attribution (CC BY) license (http://creativecommons.org/licenses/by/4.0/). 